\title{
An Extrapolation Method of the Steel Temperature Rise for Engineering Fire Resistance Design
}

\author{
TAKAHIRO ISHIHARA, TAKAO WAKAMATSU \\ Science University of Tokyo \\ Department of Architecture \\ Faculty of Science and Technology \\ Yamasaki 2641, Noda, 278-8510, Japan
}

KAZUNORI HARADA, SYUITSU YUSA

Building Research Institute

Ministry of Construction

Tatehara 1, Tsukuba 305-0802, Japan

\begin{abstract}
A theoretical method is proposed to extrapolate the steel temperature under standard fire tests for various cross sectional areas of steel and insulation thickness. The method utilizes the parameter estimation technique, where the parameter in the lumped heat transfer model is estimated to fit to the steel temperature rise in a standard fire resistance test. By using the estimated parameters, the steel temperature rise of similar assemblies can be calculated changing the steel cross sectional area and insulation thickness. An example is shown for a steel column (H-section, $300 \times 300 \times 13 \times 15)$ insulated with calcium silicate board. The extrapolated results are compared with fire test data. It is shown that the extrapolated results give conservative results for most of the cases. Thus the method is useful for engineering calculations. However, the extrapolation overestimates the time to critical temperature if the method is applied to thinner columns under more severe mechanical conditions thus identifying the limitations of this method.
\end{abstract}

KEY WORDS: fire resistance test, extrapolation method, parameter estimation, steel cross section, insulation thickness

\section{INTRODUCTION}

The fire resistance test is a widely accepted method to measure the fire resistance of 
structural elements ${ }^{1)}$. The test is mainly aimed for classification and the typical approach is to select a specimen that represents a whole category of assemblies of interest. If the test specimen passes certain criteria (typically time to load bearing failure or time to critical temperature rise in the case of columns and beams) a fire resistance time is assigned to the tested assembly. As tests are time consuming and costly, the number of tests are usually limited and often one specific test assembly only is tested. The assigned fire resistance time is also assigned to slightly different assemblies if their performances are deemed superior to the tested specimen. As was exemplified, the fire resistance test has poor connection with the actual performance.

On the other hand, an engineering approach to fire resistance is becoming more usual under the closure of performance-based code. In this approach, the design takes into account the column size (sectional and longitudinal) and insulation thickness as design variables. At this moment, analytical methods ${ }^{2}$ are the feasible way to calculate the fire exposure, thermal response of the element and mechanical behavior of the structural frame. However it is natural to make use of fire resistance test data in engineering design $^{3)}$, because a vast quantity of fire resistance test data is available within the fire community.

To make a better link to engineering design, fire resistance test data must be extrapolated to meet design conditions. Extrapolation consists of two parts, thermal behavior and mechanical behavior. Extrapolation of thermal behavior corresponds with the difference in thermal properties such as the heat capacity of steel between tested elements and the elements under consideration in the design process. Mechanical extrapolation corresponds with the difference in mechanical condition between test and design condition. Consideration can be given to utilization factor, slenderness ratio, thickness ratio and so on.

As a primary step in the development, theoretical extrapolation of the thermal response of steel columns is discussed in this paper and insulated steel columns of different cross sectional area is the scope of consideration. Using as basis one measured result on steel temperature history, the way to extrapolate over different cross sectional shape and insulation thickness is proposed using a parameter estimation technique. For this problem, a statistical method was proposed ${ }^{4)}$. In that approach, several test data were tabulated in terms of time to critical temperature (usually $500^{\circ} \mathrm{C}$ ) Then the time was correlated with parameters such as section factor (heated perimeter length over steel cross sectional area) by way of statistical regression analysis ${ }^{4}$. However, this approach needed suitable enough amount of test data, thus was costly and time consuming.

However, going back to basic principle on heat transfer, it is possible to make extrapolations theoretically and such a methodology is discussed in this study. Firstly, the thermal response of the steel column was described by a lumped thermal network model with unknown material properties. Then the "optimum" material properties were estimated so that the model prediction would best fit fire test data. Finally, using the estimated properties, the thermal responses of various column assemblies (different steel cross sectional area, different insulation thickness) were calculated and the results summarized in the form of a design chart. In addition, the rationality of this approach was checked against fire resistance test data carried out using varying insulation thickness and steel cross sectional areas. 


\section{HEAT TRANSFER MODEL}

The scope of this work is steel columns insulated by lightweight passive materials. In this case, the heat capacity of the insulation material is much smaller than that of steel. Thus, a lumped body approximation could be applied to describe the heat transfer. As shown in FIGURE 1, the heat balance of the column is described by

$\rho c A \frac{d T_{s}}{d t}=k\left(T_{f}-T_{s}\right)$

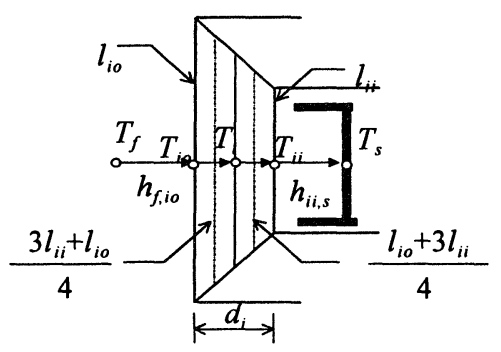

FIGURE 1 steel column under heating on four sides

And the heat capacity of the column per unit length is,

$\rho c A=\rho_{i} c_{i} A_{i}+\rho_{s} c_{s} A_{s}+c_{w} \rho_{0} w(T)-L_{w} \rho_{0} \frac{d u(T)}{d T}$,

where subscripts $i$ and $s$ denote insulation material and steel, respectively. In the case of wet insulation materials, contained water delays the steel temperature rise and the third and fourth terms were introduced to take this beneficial effect into account. The third term corresponds to the increase in heat capacity due to the existence of water. The fourth term denotes the latent heat absorption due to moisture evaporation. To evaluate the temperature-water content relationships, $w(T)$, there are several methods proposed so far. ${ }^{5 \sim 8)}$ However, we approximated that evaporation takes place in a triangular pattern in the temperature range in 80 to $120{ }^{\circ} \mathrm{C}$ for simplicity,

$-\frac{d w(T)}{d T}=w_{0}\left\{\begin{array}{ll}0 & \left(T<T_{e}-\delta\right) \\ \frac{T-\left(T_{e}-\delta\right)}{\delta^{2}} & \left(T_{e}-\delta<T<T_{e}\right) \\ \frac{\left(T_{e}+\delta\right)-T}{\delta^{2}} & \left(T<T_{e}-\delta\right) \\ 0 & \left(T<T_{e}-\delta\right)\end{array}\right.$.

This function is shown in FIGURE 2. 


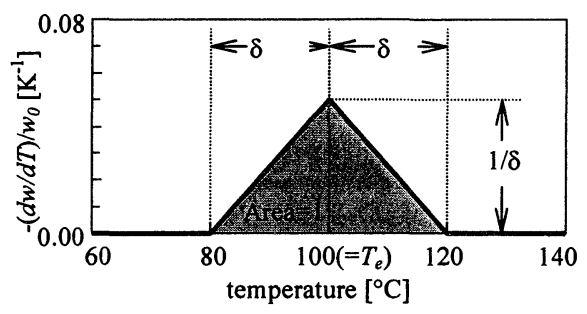

FIGURE 2 evaporation pattern of water

The thermal conductance between fire gas and steel surface is given as:

$$
k=\frac{1}{\frac{1}{h_{f, i o} l_{i o}}+\frac{1}{\frac{\lambda_{i}}{d_{i} / 2} \frac{3 l_{i o}+l_{i i}}{4}}+\frac{1}{\frac{\lambda_{i}}{d_{i} / 2} \frac{l_{i o}+3 l_{i i}}{4}}+\frac{1}{l_{i i} h_{i i s}}},
$$

where the heat transfer coefficients are,

$$
\begin{aligned}
& h_{f, i o}=h_{c, f}+\varepsilon_{f} \sigma\left(T_{f}{ }^{2}+T_{i o}{ }^{2}\right)\left(T_{f}+T_{i o}\right), \\
& h_{i i, s}=h_{c, s}+\varepsilon_{s} \sigma\left(T_{i i}{ }^{2}+T_{s}{ }^{2}\right)\left(T_{i i}+T_{s}\right) .
\end{aligned}
$$

\section{AN EXTRAPOLATION METHOD USING PARAMETER ESTIMATION TECHNIQUE}

Putting the Equation (1) into a backward difference scheme with respect to time, we get

$T_{s}^{j}=\frac{(\rho c A / \Delta t) T_{s}^{j-1}+k T_{f}^{j}}{(\rho c A / \Delta t)+k} \equiv f\left(\mathbf{T}^{j-1} ; \mathbf{p} ; \mathbf{g}\right)$,

where $\mathbf{T}^{j-1}, \mathbf{p}$ and $\mathbf{g}$ are the vector of temperatures, material property parameters and geometrical parameters,

$\mathbf{T}^{j-1}=\left\{T_{s}^{j-1}, T_{s}^{j}\right\}$,

$\mathbf{p}=\left\{\rho c A / \Delta t, h_{c, f}, \varepsilon_{f}, \lambda_{i}, h_{c, s}, \varepsilon_{s}\right\}$,

$\mathbf{g}=\left\{l_{i i}, d_{i}, l_{i o}\right\}$,

superscript $j$ denotes the $j$-th value on a discrete time axis $(t=j \Delta t)$.

This formula is satisfied only if "precise" values are substituted. Putting the fire test data as the temperature vector and assumed parameter into the vector of material properties, residuals will arise. The residual with respect to the $j$-th measurement is written as: 
$e^{j}=\overline{\mathbf{T}_{s}^{j}}-f\left(\overline{\mathbf{T}_{s}^{j-1}} ; \mathbf{p} ; \mathbf{g}\right)$

The sum of squared residuals over whole measurement period is

$S=\sum_{j}\left(e^{j}\right)^{2}=\sum_{j}\left(\overline{\mathbf{T}_{s}^{j}}-f\left(\overline{\mathbf{T}_{s}^{j-1}} ; \mathbf{p} ; \mathbf{g}\right)\right)^{2}$,

which can be minimized by the least square method with respect to the material property vector. Namely the simultaneous equations

$$
\frac{d S}{d \mathbf{p}}=\frac{d}{d \mathbf{p}}\left\{\sum_{j}\left(e^{j}\right)^{2}\right\}=0,
$$

gives the optimum parameter values $\left(\mathbf{p}_{\text {opt }}\right)$ to minimize the sum of squared residuals.

Having an optimal value for the parameter, it is possible to calculate the thermal response of assemblies similar to the tested one $\left(\mathbf{g}=\mathbf{g}_{\text {similar }}\right)$ by using Equation (7), i.e.,

$T_{s}^{j}=f\left(\mathbf{T}_{s}^{j-1} ; \mathbf{p}_{\text {opt }} ; \mathbf{g}_{\text {similar }}\right)$

as long as the thermal properties are not altered considerably by the difference in the assembly of construction.

\section{APPLICATION OF THE METHOD}

The above theory was applied to extrapolate the steel temperature rise of a specific column to columns differing in cross sectional area of the steel $\left(A_{s}\right)$ and thickness of insulation $\left(d_{i}\right)$. The extrapolated results were compared with fire resistance test data in order to examine the range of application.

\section{Fire Resistance Test}

Two series of fire resistance tests were carried out, series L (load bearing tests) ${ }^{9)}$ and $\mathrm{N}$ (non-load bearing tests). The specimens were steel columns insulated by calcium silicate board. The test specimen is shown in FIGURES 3 (a) and (b). In the test series $\mathrm{L}$, the $3.5 \mathrm{~m}$ long columns were centrally loaded with $3 \mathrm{~m}$ of effective heated length. The load ratio (applied load / allowable load at room temperature) was varied in the range of 0.29 and $1.55^{9}$. In the test series $\mathrm{N}$, short columns $(1.0 \mathrm{~m}$ long) of various section and insulation thickness were heated without applied load. The experimental conditions are summarized in TABLES 1 and 2. 

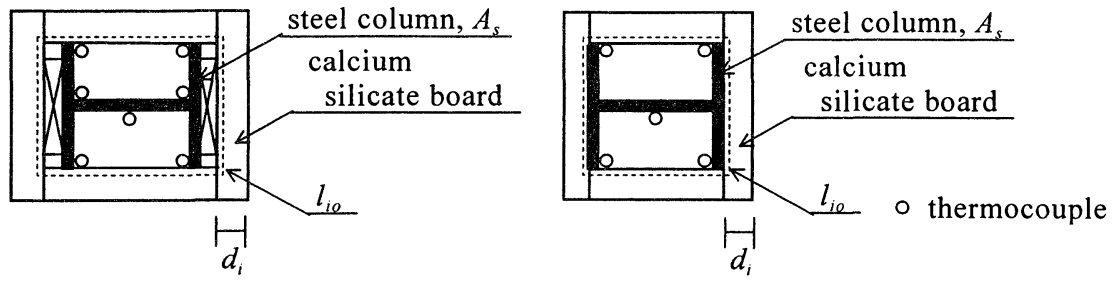

FIGURE 3 test specimen (a) load bearing tests (series L), (b) non-load bearing tests (series N)

TABLE 1 load bearing test conditions (series L)

\begin{tabular}{|c|c|c|c|c|c|c|}
\hline symbol & steel cross section* & $\begin{array}{c}\text { insulation } \\
\text { thickness } \\
\text { [mm] }\end{array}$ & $\begin{array}{l}\text { applied } \\
\text { load } \\
{[\mathrm{MN}]}\end{array}$ & $\begin{array}{c}\text { allowable load at } \\
\text { room temperature } \\
{[\mathrm{MN}]^{* *}}\end{array}$ & $\begin{array}{c}\text { load } \\
\text { ratio } \\
{[-]}\end{array}$ & $\begin{array}{l}\text { time to } \\
\text { collapse } \\
\text { [min] }\end{array}$ \\
\hline L100/40-1.55 & $\mathrm{H}-100 \times 100 \times 6 \times 8$ & 40 & 106.6 & 172.9 & 1.55 & 265 \\
\hline L200/40-1.20 & $\mathrm{H}-200 \times 200 \times 8 \times 12$ & 40 & 212.6 & 172.9 & 1.20 & 210 \\
\hline L250/40-0.59 & $\mathrm{H}-250 \times 250 \times 9 \times 14$ & 40 & 160.4 & 172.9 & 0.59 & 249 \\
\hline L300/40-0.62 & \multirow{7}{*}{$\mathrm{H}-300 \times 300 \times 10 \times 15$} & \multirow{6}{*}{40} & 208.2 & 172.9 & 0.62 & 274 \\
\hline L300/40-0.93 & & & 206 & 332.4 & 0.93 & 234 \\
\hline L300/40-1.14 & & & 75.9 & 128.9 & 1.14 & 207 \\
\hline L300/40-1.20 & & & 197.8 & 172.9 & 1.20 & 182 \\
\hline L300/40-1.23 & & & 50.7 & 172.9 & 1.23 & 180.5 \\
\hline L300/40-1.37 & & & 237.1 & 172.9 & 1.37 & 126 \\
\hline L300/25-0.29 & & 25 & 22.2 & 14.3 & 0.29 & 214 \\
\hline L400/40-0.62 & $\mathrm{H}-400 \times 400 \times 13 \times 21$ & 40 & 99.3 & 82.6 & 0.62 & 337 \\
\hline
\end{tabular}

$*$ H-web length $\times$ flange length $\times$ flange thickness $\times$ web thickness

$* *$ allowable load $=($ buckling length $) /(\text { safety factor } 1.5 \sim 2.0)^{10)}$

TABLE 2 non-load bearing test conditions (series N)

\begin{tabular}{|c|c|c|c|c|}
\hline $\begin{array}{c}\text { insulation } \\
\text { thickness [mm] }\end{array}$ & 20 & 25 & 40 & 50 \\
\hline $\mathrm{H} 100 \times 100 \times 6 \times 8$ & $\mathrm{~N} 100 / 20$ & $\mathrm{~N} 100 / 25$ & $\mathrm{~N} 100 / 40$ & $\mathrm{~N} 100 / 50$ \\
\hline $\mathrm{H} 200 \times 200 \times 8 \times 12$ & $\mathrm{~N} 200 / 20$ & $\mathrm{~N} 200 / 25$ & $\mathrm{~N} 200 / 40$ & $\mathrm{~N} 200 / 50$ \\
\hline $\mathrm{H} 300 \times 300 \times 10 \times 15$ & $\mathrm{~N} 300 / 20$ & $\mathrm{~N} 300 / 25$ & $\mathrm{~N} 300 / 40$ & - \\
\hline $\mathrm{H} 400 \times 400 \times 13 \times 21$ & $\mathrm{~N} 400 / 20$ & $\mathrm{~N} 400 / 25$ & - & - \\
\hline
\end{tabular}

\section{Overview of the Test Results}

The measured steel temperatures are shown in FIGURES 4 and 5, categorized by insulation thickness. FIGURE 4 shows the results for $20 \mathrm{~mm}$ thick insulated columns. The temperature rise greatly depends on the cross section of the steel, even though the insulation thickness is the same. The tendency is the same throughout all the insulation thickness.

Another interesting point is that the temperature rise slightly depends on load ratio. Typical example are in FIGURE 5. By comparing the curves for L300/40 and N300/40, it is clear that 
a large load ratio causes a slightly quicker steel temperature rise. Possibly the large load ratio brings about large deformations in the steel, which accelerates crack formation in the insulation materials.

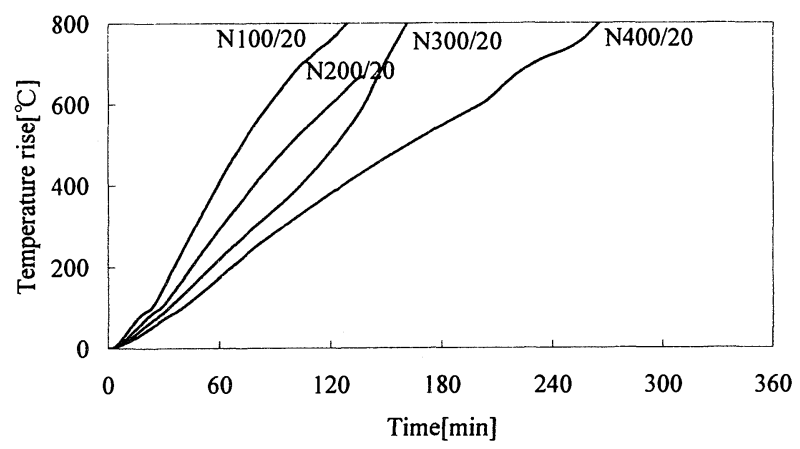

FIGURE 4 temperature rise of steel columns insulated by $20 \mathrm{~mm}$ calcium silicate board

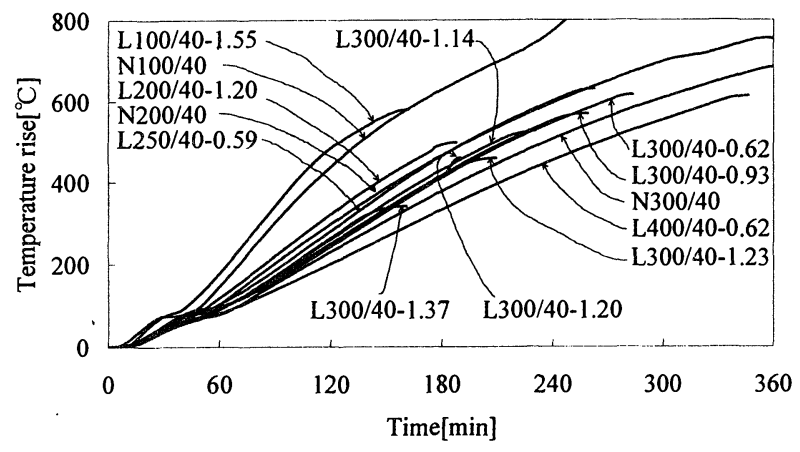

FIGURE 5 temperature rise of steel columns insulated by $40 \mathrm{~mm}$ calcium silicate board

\section{Extrapolation Example}

Among the experimental data, L300/40-1.23 was selected as a "standard" column and the material properties were determined using the test data for this standard column. Theoretically it is possible to determine all the material properties at once. However only the thermal conductivity of the insulation material was selected as a parameter to be estimated. For other properties, the values in TABLE 3 were used as prefix values. 
TABLE 3 prefixed material properties

\begin{tabular}{|l|c|c|}
\hline \multicolumn{1}{|c|}{ material property } & value & unit \\
\hline cross sectional area of insulation material, $A_{i}$ & 0.06184 & $\mathrm{~m}^{2}$ \\
\hline cross sectional area of steel column, $A_{s}$ & 0.01184 & $\mathrm{~m}^{2}$ \\
\hline specific heat of insulation material, $c_{i}$ & 920 & $\mathrm{~J} / \mathrm{kgK}$ \\
\hline $\begin{array}{l}\text { specific heat of steel column, } c_{s} \\
\text { convective heat transfer coefficient between fire gas and } \\
\text { insulation material surface, } h_{c f}\end{array}$ & 23 & $\mathrm{~J} / \mathrm{kgK}$ \\
\hline $\begin{array}{l}\text { convective heat transfer coefficient between inner surface } \\
\text { of insulation material surface and steel surface, } h_{c s}\end{array}$ & 12 & $\mathrm{~W} / \mathrm{m}^{2} \mathrm{~K}$ \\
\hline $\begin{array}{l}\text { resultant emissivity between fire gas and inner } \\
\text { surface of insulation material, } \varepsilon_{f}\end{array}$ & 0.9 & - \\
\hline $\begin{array}{l}\text { resultant emissivity between inner surface of } \\
\text { insulation material and steel surface, } \varepsilon_{s}\end{array}$ & 0.7 & - \\
\hline $\begin{array}{l}\text { density of insulation material, } \rho_{i} \\
\text { density of steel column, } \rho_{s}\end{array}$ & 622 & $\mathrm{~kg} / \mathrm{m}^{3}$ \\
\hline Stefan-Boltzmann constant, $\sigma$ & 7870 & $\mathrm{~kg} / \mathrm{m}^{3}$ \\
\hline
\end{tabular}

To estimate the optimum value, the least squares method was applied by using a subroutine embedded in a spreadsheet. The best fit steel temperature curve was obtained for $\lambda_{i}=0.149$. The resultant steel temperature curve is shown in FIGURE 6 in comparison with experimental data. As an example of extrapolation, the test condition for L400/40-0.62 was simulated. Using the estimated thermal conductivity, $\lambda_{i}=0.149$ together with the geometrical parameters for test L400/40-0.62, the steel temperature rise was calculated. The results are shown in FIGURE 7. The calculation results are in fair agreement with test data. An error of this order is not significant for design purpose as long as the error lies on the conservative side. An overall error analysis will be made in the next section.

\section{DESIGN CHART FOR THE TIME TO CRITICAL TEMPERATURE RISE}

The same process was repeated for various insulation thickness and steel cross sections covering the whole experimental range $\left(d_{i}=20 \sim 50[\mathrm{~mm}], A_{s}=0.00216 \sim 0.0219\left[\mathrm{~m}^{2}\right]\right.$, $\left.l_{i o}=0.4 \sim 1.76[\mathrm{~m}]\right)$. From the calculated steel temperature curve, the time to critical temperature rise was determined and plotted against geometrical parameters $A_{s} / l_{i o}$ and $d_{i}$. The results are shown in FIGURE 8 to 11 differing in threshold temperatures. Considering that the critical temperature for columns are given by mechanical aspects such as load ratio, the design charts were provided for several critical temperatures ranging from 350 to 500 [K-above ambient].

Bold lines are the extrapolated values. Thin lines with symbols are the experimental data. In these figures, it is found that extrapolation is feasible without large error. However it should be noted that the extrapolation results overestimate the time to critical temperature in some cases. This tendency is clear in FIGURE 8, where the overestimation tends to take place in the region of small $A_{s} / l_{i o}$. From the viewpoint of fire resistance design, the overestimation should be avoided. 


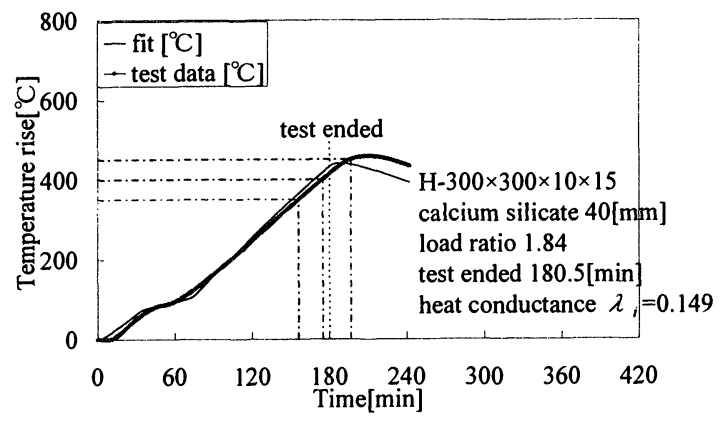

FIGURE 6 results of parameter estimation

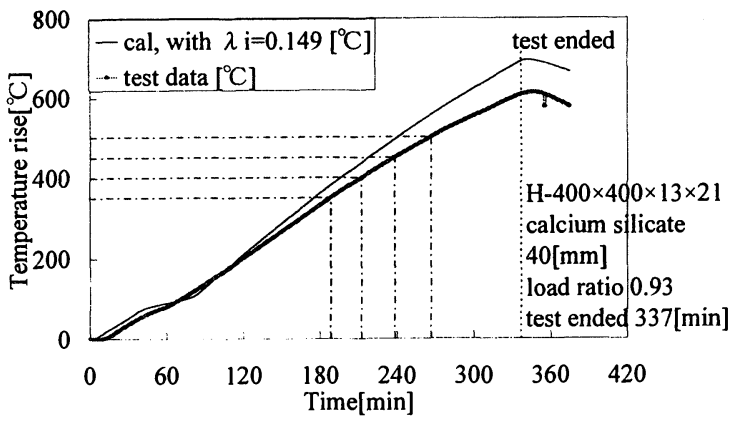

FIGURE 7 results of extrapolation

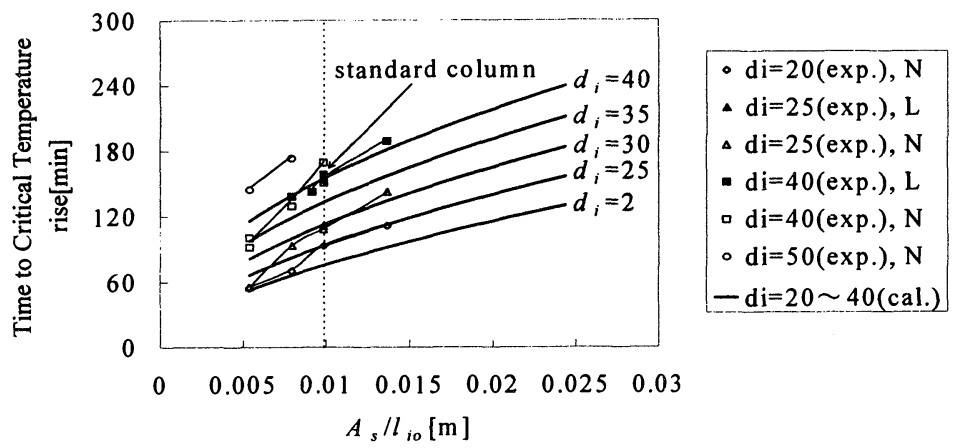

FIGURE 8 time to $350 \mathrm{~K}$ steel temperature rise 


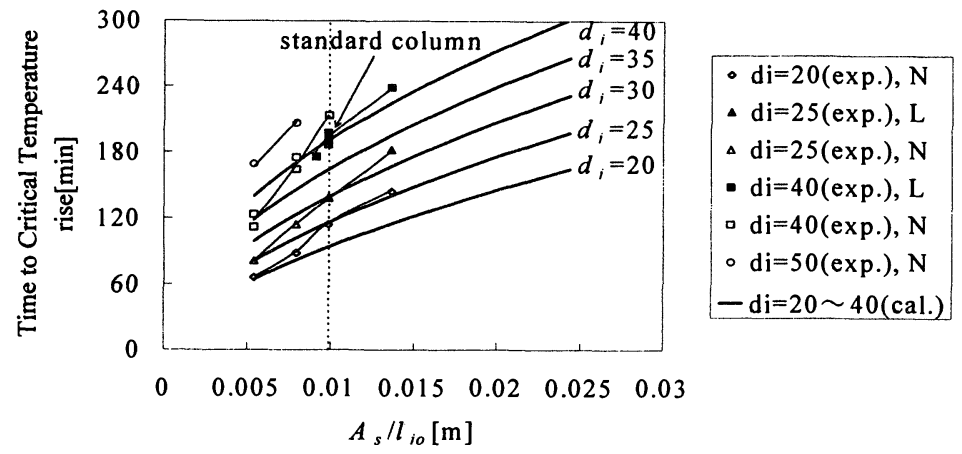

FIGURE 9 time to $400 \mathrm{~K}$ steel temperature rise

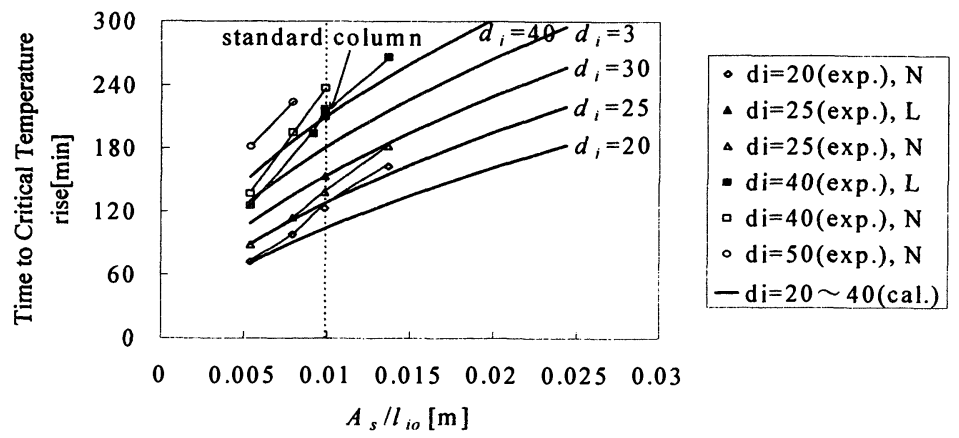

FIGURE 10 time to $450 \mathrm{~K}$ steel temperature rise

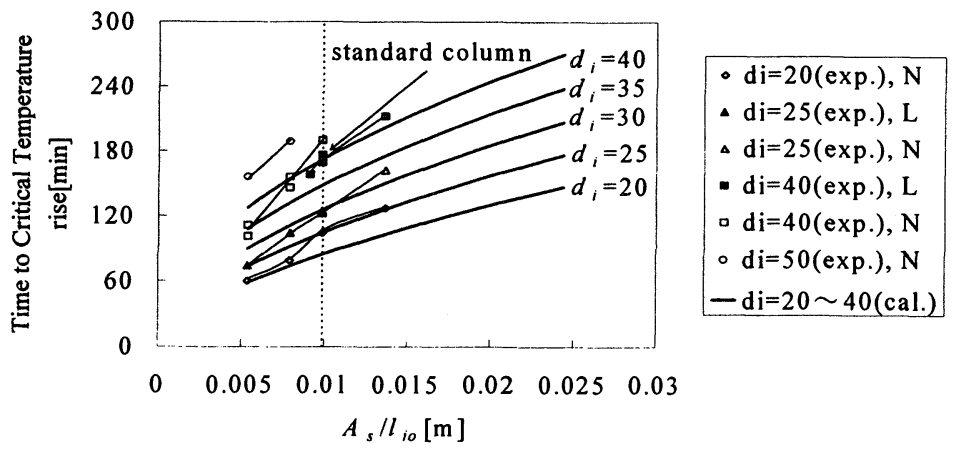

FIGURE 11 time to $500 \mathrm{~K}$ steel temperature rise 
In order to examine the extrapolation error, the measured time to critical temperature (350K rise above ambient) and extrapolated values were compared in FIGURE 12. The overestimation took place for the specimens L100/40-1.55, L200/40-1.20, L250/40$0.59, \mathrm{~N} 100 / 25$, and $\mathrm{N} 100 / 40$, in which the steel cross section was smaller than the standard column or the load ratio exceeded the standard column. Thus it can be said that the temperature extrapolation should be limited to thicker columns under milder mechanical condition (load ratio).

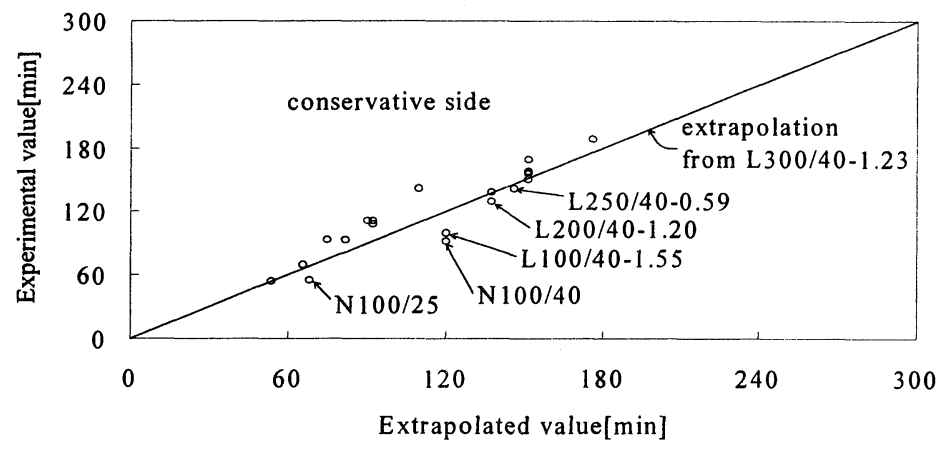

FIGURE 12 time to $350[\mathrm{~K}]$ temperature rise comparison with experimental values and values extrapolated from standard column

\section{CONCLUSIONS}

A parameter estimation method was proposed to extrapolate the steel temperature rise for various cross sectional areas of the steel and insulation thickness from a single data set obtained under the standard fire resistance test. The method utilizes the parameter estimation technique. First, the heat transfer was described by a lumped body approximation. Then, the thermal conductivity was treated as an unknown parameter to be estimated. Using fire test data (H-sectioned, $300 \times 300 \times 13 \times 15$, 3m long, fully centrally loaded), the value of thermal conductivity was estimated so that the model prediction would best fit to the experimental data. Using the estimated value of thermal conductivity, the temperature rise of the steel column assembly was calculated. As a result, it was shown that the extrapolation method gives conservative values if extrapolation is towards the thicker columns under milder mechanical conditions.

\section{NOMENCLATURE}

$\begin{array}{ll}A & \text { cross section area }\left[\mathrm{m}^{2}\right] \\ c & \text { specific heat }[\mathrm{J} / \mathrm{kgK}] \\ c_{w} & \text { specific heat of water }(=4180) \\ & {[\mathrm{J} / \mathrm{kgK}]} \\ h_{c, f}, h_{c, s} \text { convective heat transfer } \\ \text { coefficient }\left[\mathrm{W} / \mathrm{m}^{2} \mathrm{~K}\right]\end{array}$

$h_{f, i o}$ heat transfer coefficient from the gas to inner surface of insulation material $\left[\mathrm{W} / \mathrm{m}^{2} \mathrm{~K}\right]$

$h_{i i, s} \quad$ heat transfer coefficient from inner surface of insulation material to steel surface $\left[\mathrm{W} / \mathrm{m}^{2} \mathrm{~K}\right]$ 
$k \quad$ thermal conductance between the fire gas and the steel column $\left[\mathrm{W} / \mathrm{m}^{2} \mathrm{~K}\right]$

$L_{\mathrm{w}} \quad$ latent heat of water for evaporation $(=2260)[\mathrm{kJ} / \mathrm{kgK}]$

$T_{e} \quad$ evaporation temperature $(=100)\left[{ }^{\circ} \mathrm{C}\right]$

$T_{f} \quad$ heating temperature [K]

$T_{s} \quad$ steel temperature $[\mathrm{K}]$

$w_{0} \quad$ initial water content of insulation material $[\mathrm{kg} / \mathrm{kg}]$

$w(T)$ the water content of insulation material at temperature $T[\mathrm{~kg} / \mathrm{kg}]$

$-d w / d T$ quantity of evaporation per unit temperature rise $[\mathrm{kg} / \mathrm{kg} \cdot \mathrm{K}]$ $\delta \quad$ width of evaporation temperature range $(=20)[\mathrm{K}]$.

$\varepsilon_{f} \quad$ resultant emissivity between fire gas and insulation material surface [-]

$\varepsilon_{s} \quad$ resultant emissivity between inner surface of insulation material and steel surface [-]

$\rho$ density $\left[\mathrm{kg} / \mathrm{m}^{3}\right]$

$\sigma \quad$ Stefan-Boltzmann constant $\left[\mathrm{kW} / \mathrm{m}^{2} \mathrm{~K}^{4}\right]$

$\Delta t \quad$ time increment $[\mathrm{s}]$

\section{REFERENCE}

1. ISO/TR 834 Fire Resistance Tests-Elements of Construction

2. ISO/CD 12471, Computational Structural Fire Design, 1998

3. Kokkala, M., "Fire Test Data for Fire Safety Engineering", Performance-Based Fire Safety Design (Workshop), Victoria University of Technology, 1997

4. Fire Protection for Structural Steel in Building, 2nd Ed., Assoc. of Specialist Fire Protection Contractors and Manufacturers Limited, 1975

5. Kawagoe, K., "Estimation of Fire Temperature Rise Curves in Concrete Buildings and its Application", Bull. of Fire Prevention Society of Japan Vol. 13. No. 1, 1962

6. Wakamatsu, T., "Heat Flow Analysis of Building Members during Fire Exposure, First and Second Reports", Transactions of the Architectural Institute of Japan No. 109 and 111, 1965 (in Japanese)

7. Harmathy, T., Z., "Simultaneous Moisture and Heat Transfer in Porous Systems with Particular Reference to Drying", Industrial and Engineering ChemistryEundamentals, Vol. 8, pp. 92-103, 1969

8. Harada, K., Terai, T., "Heat and Mass Transfer in an Intensely Heated Mortar Wall", Eire Safety Science, Vol. 3, (Proceedings of the third International Symposium on Fire Safety Science, Edgingburh), pp. 780-781, 1991

9. Okamura, Y., Harima, M., "Estimation of Fire Resistance of Steel Columns, Part 1 and 2", Summaries of Technical Papers of Annual Meeting Architectural Institute of Japan, 1997 (in Japanese)

10. Design Standard for Steel Structures, Architectural Institute of Japan, pp. 97-99, 1970 